\title{
Tissue remodelling in chronic bronchial diseases: from the epithelial to mesenchymal phenotype
}

\author{
Mallory Pain 1 , Olga Bermudez², Philippe Lacoste ${ }^{1}$, Pierre-Joseph Royer ${ }^{1}$, \\ Karine Botturi' ${ }^{1}$, Adrien Tissot ${ }^{1}$, Sophie Brouard ${ }^{3}$, Oliver Eickelberg ${ }^{2}$ and \\ Antoine Magnan'
}

\begin{abstract}
Affiliations: 'UMRS 1087 CNRS UMR6291, l'Institut du Thorax, Université de Nantes, CHU de Nantes, Nantes, and ${ }^{3}$ UMRS 1064, Institut de Transplantation Úrologie Néphrologie, CHU de Nantes, Nantes, France. ${ }^{2}$ Comprehensive Pneumology Center, University Hospital of the Ludwig-Maximilians-University Munich and Helmholtz Zentrum München, Munich, Germany.
\end{abstract}

Correspondence: M. Pain, UMRS 1087, l'Institut du Thorax, Université de Nantes, 8 quai Moncousu, 44007, Nantes, France. E-mail: Mallory.painduniv-nantes.fr

ABSTRACT Airway remodelling is a critical feature of chronic bronchial diseases, characterised by aberrant repair of the epithelium and accumulation of fibroblasts, which contribute to extracellular matrix (ECM) deposition resulting in fixed bronchial obstruction. Recently, epithelial-mesenchymal transition (EMT) has been identified as a new source of fibroblasts that could contribute to the remodelling of the airways. This phenomenon consists of the loss of the epithelial phenotype by bronchial epithelial cells and the acquisition of a mesenchymal phenotype. These cells are then able to migrate and secrete ECM molecules. Herein, we review the different types of EMT. We will then focus on the signalling pathways that are involved, such as transforming growth factor- $\beta$ and Wnt, as well as the more recently described Sonic Hedgehog pathway. Finally, we will highlight the implication of EMT in airway remodelling in specific chronic bronchial pathologies, such as asthma, chronic obstructive pulmonary disease and bronchiolitis obliterans following lung transplantation. Despite the limitations of in vitro models, future studies of EMT in vivo are warranted to shed new light on the pathomechanisms of bronchial obstruction.

@ERSpublications

Epithelial-mesenchymal transition in chronic bronchial remodelling diseases http://ow.ly/q5I3C

\section{Introduction}

The epithelial-mesenchymal transition (EMT) refers to a phenomenon in which a polarised epithelium with cell-cell contacts that is attached to the basal membrane differentiates into fibroblast-type mesenchymal cells [1]. This process demonstrates the plasticity of the cells that can also undergo the reverse process, the mesenchymal-epithelial transition (MET) [2]. On the one hand, EMT involves the loss of epithelial polarity due to the disassembly of cell-cell contacts such as adherent junctions (E-cadherin) or tight junctions (zonula occludens-1) and, on the other hand, involves the expression of mesenchymal proteins such as $\alpha$-smooth muscle actin (SMA), vimentin and/or fibronectin [3, 4]. Alterations in the expression of

Received: June 132013 | Accepted after revision: July 102013

Support statement: The research programme is supported by the Institut Thématique Multi Organisme ImmunoHémato-Pneumologie of the French National Alliance for Life Sciences and Health (Paris, France), Vaincre la Mucoviscidose (Paris), Agence de Biomédecine (Paris), INSERM (Paris), Région Pays de La Loire (Nantes, France), Institut de Recherche en Santé Respiratoire des Pays de la Loire (Nantes) and Fondation du soufflé (Paris).

Conflict of interest: Disclosures can be found alongside the online version of this article at err.ersjournals.com

Provenance: Submitted article, peer reviewed.

Copyright OERS 2014. ERR articles are open access and distributed under the terms of the Creative Commons Attribution Non-Commercial Licence 3.0. 
extracellular matrix (ECM) components (fibronectin and collagens) or degrading enzymes (matrix metalloproteinases (MMP)2 and MMP9) leads to the loss of adherence to the ECM and gives the cells a migratory capacity.

EMT is a physiological phenomenon involved in embryogenesis during the trans-differentiation of epithelial cells into mesenchymal cells [2]. EMT can contribute to the development of cancer, and is implicated in the invasion of tumoural cells and in metastatic migration, as has been demonstrated in models of ovarian, colon, oesophageal and bronchial cancers [5-9].

EMT also participates in healing and tissue repair. The implication of EMT in these processes has been demonstrated in the kidney, the eye and liver fibrosis [10-12]. In inflammatory contexts and during chronic aggression of the epithelium, EMT could generate the fibroblasts needed for the tissue regeneration. However, EMT can persist beyond the inflammation process leading to pathological fibrosis, as in idiopathic pulmonary fibrosis (IPF) [13-15]. In this disease, alveolar epithelial cells are elongated with a modification in the expression of cytokeratins. In addition, these cells are able to secrete pro-fibrotic factors, such as transforming growth factor (TGF)- $\beta$, connective tissue growth factor (CTGF), platelet-derived growth factor (PDGF), endothelin-1 and tumour necrosis factor (TNF)- $\alpha$, and respond to these factors by modifying their morphology and differentiating into fibroblasts [16-22]. Studies in vitro in alveolar cell lines from rats (RLE-6TN), mice (AT2) and humans (A549) have demonstrated the occurrence of EMT in these cells in response to TGF- $\beta[15,23,24]$. Likewise, alveolar cells can secrete MMPs, contributing to tissue remodelling $[25,26]$.

Recently, the bronchial epithelium has been studied as a potential source of fibroblasts and myofibroblasts in the chronic remodelling of airways. This bronchial remodelling is one of the main characteristics of diseases such as asthma, chronic obstructive pulmonary disease (COPD) and bronchiolitis obliterans (BO). In these diseases, repeated aggression of the respiratory epithelium (allergens, allogenicity, cycles of infections, cigarette smoke and atmospheric pollutants) leads to chronic inflammation. In response to chronic inflammation, aberrant or uncontrolled tissue repair gives rise to an excessive fibroblastic response contributing to the production of ECM, tissue remodelling and fixed bronchial obstruction. The origin of the fibroblasts responsible for the accumulation of ECM has not yet been determined. They could derive from the proliferation of resident fibroblasts or from the recruitment of progenitor cells.

The role of EMT in these pathologies is not well described but this phenomenon could contribute to the pool of mesenchymal cells, allowing the activation and proliferation of fibroblasts and resident myofibroblasts that are responsible for the accumulation of ECM [27-30]. In this review we propose the description of different types of EMT and will highlight the different signalling pathways involved, including the TGF- $\beta$, Wnt and Sonic Hedgehog (Shh) pathways. Finally, we review the implication of EMT in the remodelling of severe chronic inflammatory bronchial diseases such as asthma, COPD and BO following lung transplantation.

\section{EMT: classification and evidence}

EMT can be classified into three categories with functional differences. Type I EMT is associated with physiological processes involved in tissue and organ formation during embryogenesis [31]. Type I EMT is implicated in the formation of the mesoderm from the epithelium and in the generation of neural crest cells. In this way, the primary mesenchyma is formed from the epiblast (primitive epithelium). This transition is reversible and the primary mesenchyma can undergo a re-transformation into secondary epithelium. This MET is required for finishing the process of cell differentiation and for defining the threedimensional structure of the organs. These cycles of EMT and MET are involved in the development of the liver, as well as in the formation of the heart or islets of Langerhans [32-35].

Type III EMT refers to the acquisition of a migratory phenotype by malignant epithelial cells and is associated with tumour invasiveness [36, 37]. During metastasis, epithelial cells lose their polarity and detach from the basal membrane. These cells can migrate through the ECM/tissue and reach the blood circulation to find new metastatic sites to target (fig. 1). Different studies have revealed that metastatic cells express mesenchymal markers such as $\alpha$-SMA, fibroblast specific protein-1 (FSP1; also known as S100A4), vimentin or desmin [38]. These markers are particularly expressed in the cells localised in the invasion front of the tumour and are associated with the detachment of cells from the ECM and the colonisation of new organs $[2,7,39]$.

EMT can also participate in the process of healing, contributing to the pool of mesenchymal cells needed for tissue regeneration. However, in response to chronic inflammatory conditions, the processes related to tissue repair become excessive and EMT (type II) is then associated with tissue fibrosis. In this fibrotic process, fibroblasts accumulate secreting collagen fibres, leading to dysfunction of the organ (fig. 2). Using 


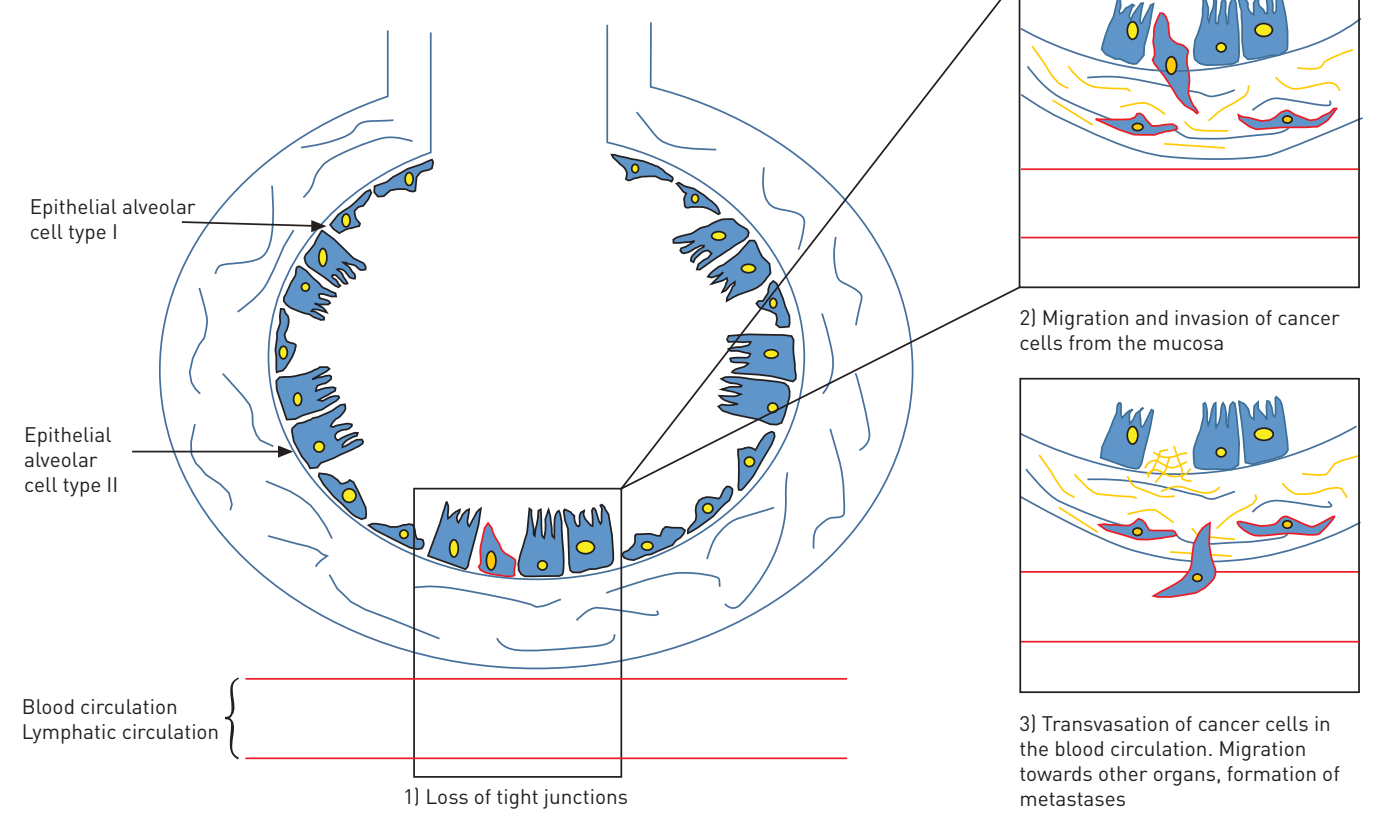

FIGURE 1 Epithelial-mesenchymal transition type III; an example of alveolar carcinoma.

transgenic mice in a model of unilateral ureteral obstruction, IWANO et al. [40] have demonstrated that epithelial cells from the kidney undergo EMT, thus contributing to the fibrosis of the organ. Other studies have shown that EMT is associated with kidney, liver, lung and intestine fibrosis [23, 41].

Identification of EMT requires a selection of specific markers. The loss of the epithelial phenotype is characterised by a decrease in the expression of epithelial proteins including junction proteins (E-cadherin and zonula occludens-1), cytokeratins of the cytoskeleton and a decreased expression of the surface protein MUC1 (Mucin 1, cell surface associated). Although the loss of those proteins has been largely described during EMT, the acquisition of mesenchymal markers is more difficult to prove. Markers used for defining the mesenchymal phenotype are vimentin, $\alpha$-SMA, FSP1, desmin, fibronectin and the production of MMPs [42]. Nonetheless, vimentin is not expressed by all fibroblasts and is also present in leukocytes and endothelial cells [43]. However, $\alpha$-SMA is expressed by myofibroblasts that represent only a fraction of the activated fibroblasts [40,44]. Finally, FSP1 (S100A4) is expressed by inflammatory cells, as well as endothelial cells and smooth muscle cells [45-48]. The diversity of mesenchymal markers highlights the complexity of EMT and the need to use different markers to characterise this process.

\section{Induction of EMT and cell signalling}

Mechanisms of EMT

The complexity of EMT is due to the diversity of the factors involved and the different effects the factors have depending on the context. The structure of the cytoskeleton can directly induce EMT by disrupting cell-cell or cell-ECM interactions [4,49] and by inducing the expression of Snail and Slug, regulating the expression of proteins involved in EMT such as E-cadherin and desmoplakin. Mesenchymal markers such as vimentin and fibronectin are upregulated and redistributed [50-53]. The cell environment is very important and pleiotropic signals like reactive oxygen species have an effect in different signalling pathways leading to EMT [54-56]. In addition, EMT can be induced by various growth factors, including fibroblast growth factor (FGF)2, epidermal growth factor, CTGF, insulin-like growth factor (IGF)2, interleukin (IL)-1 and hepatocyte growth factor (HGF). These growth factors have different effects depending on the context in which they are secreted. In the presence of IGF2, $\beta$-catenin (proteins linking the cytoskeleton with adherent junctions) dissociates from E-cadherin on the cell surface and is redistributed to the nucleus [57]. FGF2 is considered as a potential factor inducing EMT in kidney cells, and stimulating the secretion of MMP2 and MMP9 which are involved in the degradation of the basal membrane [58]. HGF is one of the growth factors involved in proliferation, migration, differentiation and cell survival. The effect of HGF is associated with the action of the transcription factor Snail, which decreases the expression of E-cadherin and activates mesenchymal genes. HGF is mainly involved in type I EMT, during the formation of somites or cardiac buds [59]. Among the growth factors involved in EMT, TGF- $\beta$ remains the most studied. 
FIGURE 2 Epithelial-mesenchymal transition (EMT) type II in bronchial remodelling. ECM: extracellular matrix.

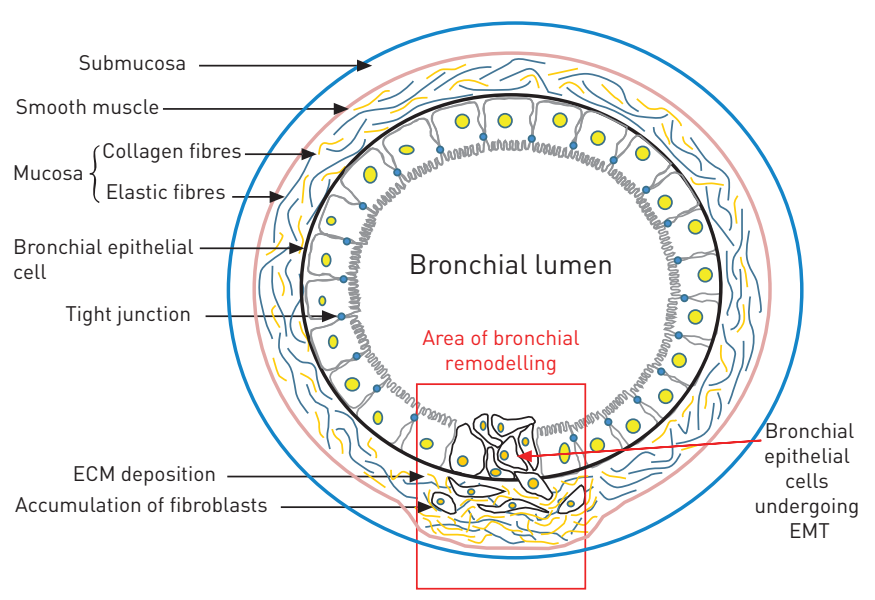

The central role of TGF- $\beta$

TGF- $\beta$ is a cytokine with different roles during development, inflammation, repair, proliferation and cell differentiation. This cytokine has largely been described as an inducer of type I EMT, especially in the formation of neural crests and cardiac valves, and during palatine fusion [60-62]. In pathological conditions such as lung cancer, TGF- $\beta$ has a dual role. In the first stages of the pathology TGF- $\beta$ acts as a tumour suppressor, but in the late stages of cancer TGF- $\beta$ favours type III EMT contributing to the dissemination of metastases. In vitro studies in different pulmonary epithelial cells obtained from healthy donors have shown that exposure to TGF- $\beta$ induces a mesenchymal phenotype in these cells [29, 63-68].

TGF- $\beta$ is a ubiquitous cytokine that is present in several isoforms (TGF- $\beta 1$, TGF- $\beta 2$, and TGF- $\beta 3$ ). TGF- $\beta$ binding induces the dimerisation of the type I and II TGF- $\beta$ receptors. The type II receptor, which has constitutive kinase activity, phosphorylates the type I receptor activating the canonic TGF- $\beta$ signalling cascade involving the intracellular proteins of the Smad family. Phosphorylated TGF- $\beta$ receptors phosphorylate and activate Smad2 and Smad3 [69]. The Smad2/3 dimer forms a complex with Smad 4, named the Smad protein complex. This complex then translocates to the nucleus where it participates in the transcriptional regulation of target genes [70,71] (fig. 3). The Smad complex then represses the expression of E-cadherin by the transcription factors Snaill and Snail2 (snail and slug, respectively) [50, 72]. Snail induces the expression of mesenchymal proteins like N-cadherin, fibronectin, vitronectine and MMPs (fig. 3) $[73,74]$.

Using Smad3 knock-out mice, ZAVADIL et al. [75] have shown that Smad3 was necessary for EMT induction by TGF- $\beta$ [75]. Furthermore, recent studies have demonstrated that Smad 3 controls the majority of genes involved in EMT [38]. Thus, inhibition of the TGF- $\beta$ pathway appears to be an interesting therapeutic strategy for inhibiting EMT. Indeed, inhibitors of TGF- $\beta$ or its receptors decrease metastasis and/or affect the invasive properties of cells in vivo [76-78]. There are some endogenous proteins that act as inhibitors of TGF- $\beta$ signalling. For instance, Smad7 is associated with the activated receptor TGF- $\beta 1$, preventing the phosphorylation of Smad2/3. Bone morphogenetic protein (BMP)7, a member of the TGF- $\beta$ superfamily, uses TGF- $\beta$ receptors to induce the formation of a Smad complex (Smad 1 and 4) and its nuclear translocation (fig. 3). This complex represses the transcription of EMT Zeb1 (zinc finger E box binding homeobox) and Snaill transcription. In a murine model of kidney fibrosis, EMT induced by TGF- $\beta$ can be inhibited by BMP7 [79-81]. However, in the bronchial epithelial cells (BEC) BMP7 is not effective for reverting EMT [63]. This suggests that EMT mechanisms depend on the cell type and tissue [82]. Recently, GARDNER et al. [65] identified a new therapeutic target, TAK1, which could be involved in the induction of EMT in the bronchial epithelium by TGF- $\beta$ and TNF- $\alpha$.

The induction of EMT by TGF- $\beta$ is mainly dependent on Smad but can also implicate other pathways, acting in synergy with Smad signalling. Indeed, TGF- $\beta$ can activate p38, mitogen activated protein kinase and phosphatidylinositol 3-kinase pathways implicated in type III EMT (fig. 3) [83, 84]. The RhoA pathway can be inhibited by TGF- $\beta$, destabilising tight junctions. The mitogen activated protein kinase pathway (Ras/Raf) contributes to the autocrine secretion of TGF- $\beta$ [85]. In some cases the activation of these proteins is necessary, but not sufficient, for inducing EMT [86]. 


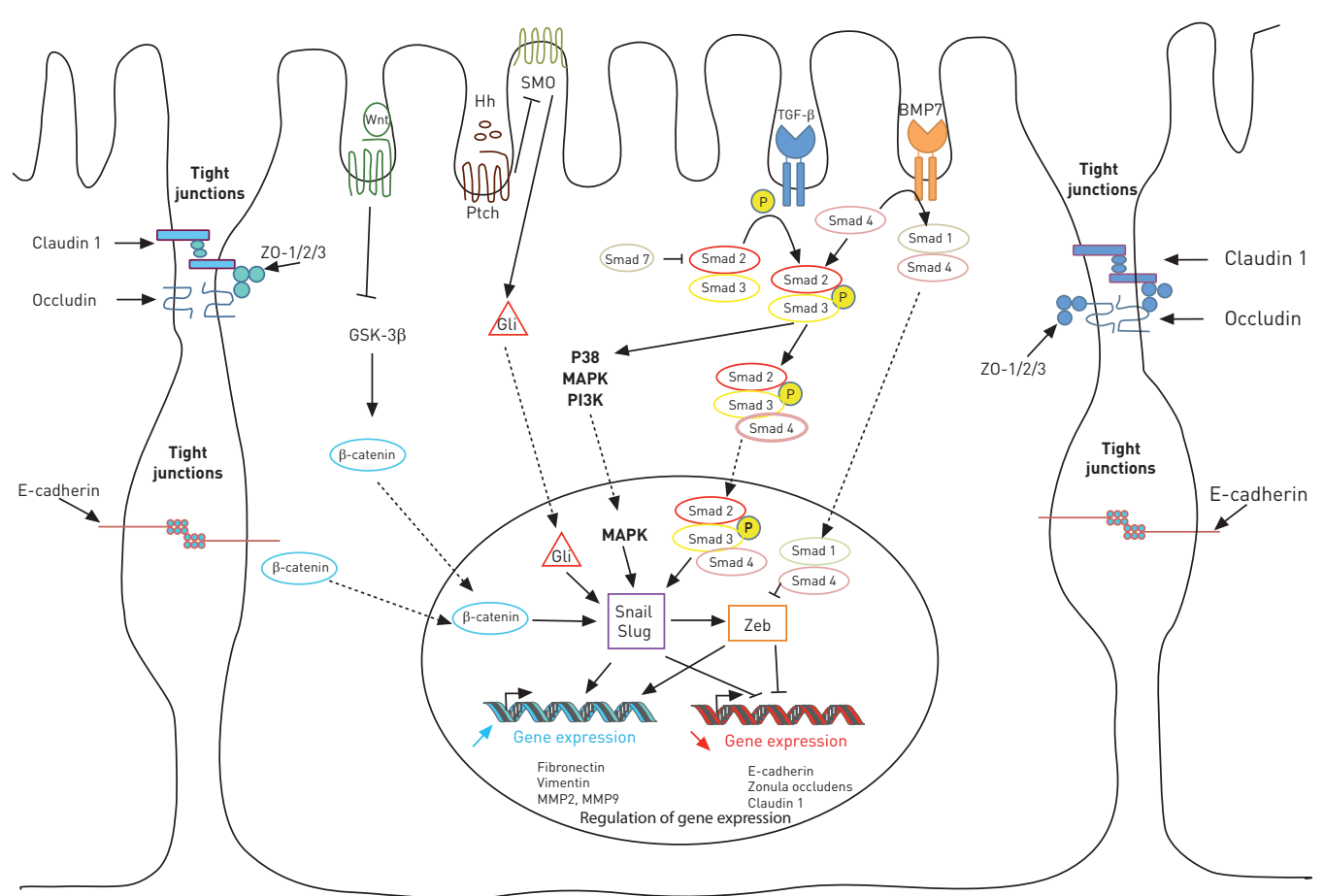

FIGURE 3 Cell signalling involved in epithelial-mesenchymal transition. ZO: zonula occudens; Wnt: wingless tail; Hh: Hedgehog; SMO: Smoothened; GSK-3 $\beta$ : glycogen synthase kinase-3 $\beta$; Ptch: Patched; MAPK: mitogen activated protein kinase; PI3K: phosphatidylinositol 3-kinase; Zeb: zinc finger E box binding homeobox; MMP: matrix metalloproteinase; TGF: transforming growth factor; BMP7: bone morphogenetic protein 7; P: phosphate.

\section{Other signalling pathways involved in EMT}

Wnt ligand

The $\beta$-catenin pathway, induced by the ligand Wnt (wingless tail), is involved in the mechanisms of lung remodelling in pathological conditions [87-90]. Briefly, the ligand Wnt binds to the receptor Frizzled (Fzd) inducing its phosphorylation and the inactivation of glycogen synthase kinase- $3 \beta$. This contributes to the cytosolic accumulation of $\beta$-catenin and its translocation to the nucleus (fig. 3), where it can interact with lymphoid-enhancer binding factor and T-cell-specific transcription factor, inducing the transcription of target genes, such as those encoding C-myc and Cyclin D [91]. Thus, leading to a modification of cytokeratins expression and the reorganisation of the cytoskeleton. The canonical Wnt pathway has been described as a mediator of TGF- $\beta$ signalling in alveolar type II cells and pulmonary fibrosis [92, 93]. Other signalling pathways such as Notch, nuclear factor- $\kappa \mathrm{B}$ and Shh have also been shown to participate in EMT $[86,94,95]$.

\section{Hedgehog signalling}

The Hedgehog gene $(\mathrm{Hh})$ was first identified during a screening of genetic mutations involved in the segmentation of Drosophila larvae [96]. Orthologs of Hh have been described since in the vertebrates. There are three genes coding for the ligand Hh in vertebrates: Shh, Indian Hedgehog (Ihh) and Desert Hedgehog (Dhh). Among these three genes, Shh is the most broadly expressed in mammalian tissues [97]. The presence of Shh releases Smoothened (SMO) from the inhibition exerted by the receptor Patched (Ptch). $\mathrm{SMO}$ is a $\mathrm{G}$ protein associated with the receptor that transduces $\mathrm{Hh}$ signalling inside the cell (fig. 3). The activation of the Shh pathway results in the nuclear translocation of the transcription factor Gli (fig. 3), which regulates the expression of genes involved in proliferation, such as cyclins, and genes of the $\mathrm{Hh}$ pathway itself, such as Gli and Ptch [98]. The Shh pathway is activated during lung repair and the physiological development of the lung [99]. During animal development, Shh is expressed in the airway epithelium and is essential for regulating epithelial-mesenchymal crosstalk in the lung. The Hh pathway is essential for lung formation as Shh knockout embryos exhibit severe defects in the development of the lung due to failure of branching and tissue growth [100-102]. Moreover, Gli2-knockout mice die at birth with lungs presenting a reduced size and defects in the ramification [103]. In adult tissues, growing evidence has highlighted the importance of the Hh pathway in cell migration. The canonical Hh pathway, dependent on SMO and the transcription factor Gli, is also implicated in cell migration and invasion through the regulation of genes associated with EMT. The knockout of Gli1 reduces the expression of Snail and MMP9 
and increases the expression of E-cadherin [104]. In addition, when the expression of Gli1 is induced in epithelial cells (using a tetracyclin-controlled transcriptional activation system), Snail is expressed in a fast and considerable manner [105]. In mice, the overexpression of Gli1 in the skin induces the formation of skin lesions and the loss of E-cadherin expression [105]. In pancreatic cancer cells, expression of E-cadherin is independent of Snail and Slug but directly regulated by Gli1 [106]. The inhibition of the Hh pathway with cyclopamine, a steroid that blocks SMO, decreases the expression of Gli1 and Gli2, but also the expression of Sip1, Snail2 and Twist2 [107]. Thus, the Hh pathway, through canonical and non-canonical signalling, is involved in the regulation of genes associated with EMT and regulates cell migration. The impact of the $\mathrm{Hh}$ pathway in cell migration and mesenchymal transformation can have important consequences in pathological processes such as fibrosis. In mice models of nonalcoholic fatty liver disease, EMT in the liver occurs with the concomitant activation of the Hh pathway and is associated with liver fibrosis. Furthermore, in Ptch+/- mice, the over-activation of the Hh pathway parallels an increase in EMT and an aggravated liver fibrosis [108]. In the lung, expression of the Shh ligand is increased in patients with usual interstitial pneumonia, nonspecific interstitial pneumonia [109], cryptogenic pneumonia [110] or IPF [111, 112]. Recent studies in IPF lungs have revealed distinct expression of Hh-related proteins in IPF tissues $[111,112]$. Shh is expressed in bronchial and alveolar epithelial cells in fibrotic areas while Ptch1 is observed in fibroblasts, interstitial inflammatory cells and the hyperplastic epithelium. The G protein-coupled receptor SMO is detected in the hyperplastic epithelium, interstitial inflammatory cells and mesenchymal cells, forming fibroblast foci in IPF tissues. The Hh-specific transcription factors, Gli1-3, are found in IPF lungs with a different pattern of expression. While Glil is detected in the nucleus of epithelial cells and fibroblasts and in inflammatory cells, Gli2 has a nuclear distribution in alveolar epithelial cells and Gli3 shows a weak expression in fibroblastic foci. Together, these data show that Hh-related molecules are highly expressed in IPF lungs, indicating an activation of the Hh pathway in this type of lung fibrosis. Moreover, in fibroblasts, Shh increases the synthesis of proteins related to ECM, such as collagen and fibronectin $[112,113]$. Interestingly, inhibition of the Hh pathway reduces the expression of $\alpha$-SMA, collagen 1 and fibronectin and abrogates the effect of TGF- $\beta$ on these proteins [111], highlighting the importance of the TGF- $\beta / \mathrm{Hh}$ crosstalk that may promote a mesenchymal phenotype in pathological contexts. In different types of lung cancer, the Shh pathway has also been found to be re-activated [99, 113-116], and is involved in the mesenchymal transition of tumoural cells associated with the formation of metastases. In a model of lung metastases, colon carcinoma cells injected into nude mice induced pulmonary lesions. In this model, the expression of a short hairpin (sh)RNA against SMO inhibits the metastatic growth. In addition, cells from colon carcinoma expressing shRNA against Ptch1 or Gli1 lose epithelial morphology, and increase their capacity for migration and expression of EMT-related genes, such as FOXC2, vimentin, Snaill and ZFHX1B, while the expression of E-cadherin is decreased [117]. Shh can stimulate the small GTPases Rac1 and RhoA, resulting in the migration of the cells in a SMO-dependant but Gli-independent mechanism, which is therefore related to a "non-canonical" $\mathrm{Hh}$ pathway [118, 119].

In summary, studies in the lung and other organs have revealed the involvement of the Shh pathway in EMT in vitro and in vivo. The impact of Shh in cell migration can also be due to the interaction between this pathway and other signalling cascades such as TGF- $\beta$, one of the main factors involved in EMT. Evidence has shown an interaction between the Shh and TGF- $\beta$ Smad pathway during development, but also in adult tissues [111, 120-122]. This type of interaction can enhance EMT effects in bronchial chronic lung diseases.

\section{EMT in chronic bronchial diseases \\ EMT and allergic asthma}

Asthma is characterised by the remodelling of airways, including subepithelial fibrosis, hyperplasia of myofibroblasts and myocytes, and an increase in smooth muscle fibres [123]. In histological samples from asthmatics, myofibroblasts have been found in close proximity to smooth muscle and lamina reticularis $[124,125]$. However, the origin of these myofibroblasts remains unclear. Recently, the involvement of EMT in the bronchial remodelling of asthmatic patients has been proposed [40].

The respiratory epithelium constitutes a physical barrier protecting the organism against infections, harmful particles or allergens. After chronic aggression, the epithelium is able to modulate the innate immune response and adaptive immune response by interacting with cells from the immune system, but also by secreting soluble factors such as TGF- $\beta$, epidermal growth factor, FGF2, IGF1, PDGF and endothelin-1 $[126,127]$. All these modifications contribute to the proliferation and differentiation of fibroblasts and myofibroblasts, and to the accumulation of fibronectin and collagen in the lamina reticularis leading to the thickening of the bronchial wall. Studies in different models of allergic asthma in vivo and investigations in vitro with BEC of asthmatic patients have shown that circulating progenitors of fibroblasts (fibrocytes) are recruited during the repair of the epithelium. In bronchial biopsies, NiHLBERG et al. [128] have found that fibrocytes present in the basal membrane of patients with moderate asthma correlated with the thickening 
of this membrane. This type of fibrocyte was also found in the bronchoalveolar lavage (BAL) of these patients suggesting that circulating fibrocytes differentiated into myofibroblasts [128]. Indeed, it is not clear whether the fibrocytes are able to differentiate into myofibroblasts or whether they stimulate the differentiation and proliferation of other progenitors or mesenchymal resident cells.

With the aim of identifying EMT in vivo, JoHnson et al. [129] have developed a murine transgenic model in which airway epithelial cells express the lac-Z reporter gene. After 5 days of exposure to house dust mite allergen epithelial cells underwent EMT, co-expressed the protein S100A4 and accumulated in the smooth muscle. Other epithelial cells co-expressing vimentin were found in the subepithelial region. These results suggest that EMT is implicated in the bronchial remodelling associated with asthma [129]. This is in agreement with previous reports demonstrating that exposure of epithelial cells to proteolytically active allergens such as Der p 1, a major mite allergen [64, 130], or to some pollen allergens [131] induced the degradation of the epithelium. Other studies in bronchial cell lines exposed to mite extracts have shown that the proteolytic action of this allergen occurs in the cell-cell contacts, releasing $\beta$-catenins from adherent junctions [64]. Compared with TGF- $\beta$, mite extract alone is not able to induce EMT. Yet in combination with TGF- $\beta$, it enhances the expression of EMT markers. These results highlight the importance of TGF- $\beta$ in EMT in asthma $[64,129]$ and elevated levels of TGF- $\beta$ have been reported in BAL and bronchial biopsies of asthmatic patients $[132,133]$. The increase of TGF- $\beta$ correlates with airflow obstruction and airway wall thickening, and is not changed despite oral treatment with corticosteroids [134, 135]. Finally, НACKETT et al. [63] demonstrated the induction of EMT in primary epithelial cells differentiated in the air-liquid interface after TGF- $\beta$ exposure. In this model of culture, EMT was localised in basal cells (identified by cytokeratin 5 and p63 expression) [63]. Moreover, EMT was dependent on Smad3. The inhibition of Smad3 by RNA interference stabilised E-cadherin expression and avoids expression of mesenchymal proteins such as fibronectin. Nonetheless, the role of TGF- $\beta 1$ in asthma-associated EMT is not completely understood. For instance, treatment of BEC with BMP7, an inhibitor of TGF- $\beta$, does not reverse EMT, as is the case in murine models of kidney fibrosis. This could be due to a dose-dependent effect of BMP7, an organ/tissue specific effect $[63,67]$, or other signalling pathways involved in asthma. In an in vitro model using BEC and the Beas-2b cell line, DoERner et al. [67] suggested a synergistic effect between TGF- $\beta$ and IL1- $\beta$. Indeed, the culture of bronchial primary cells with IL-1 $\beta$ induced a decrease in the expression of E-cadherin and an increase in the expression of tenascin C, a component of ECM. Co-treatment with TGF- $\beta$ and IL-1 $\beta$ accentuated these changes. These results suggest that the inflammatory context plays an important role in EMT. Nevertheless, in the same study, glucocorticoids did not have any effect in EMT. Future studies should elucidate the role of inflammatory pathways insensitive to glucocorticoids such as IL-17, TNF- $\alpha$ or interferon $\gamma$ in EMT.

\section{EMT and COPD}

COPD is characterised by the progressive obstruction of the airways, mainly due to inflammation induced by the inhalation of cigarette smoke [136-138]. Chronic exposure to cigarette smoke induces the infiltration of inflammatory cells in the mucosa, sub-mucosa and glandular tissue. This causes the secretion of mucus by hyperplasic epithelial cells and thickening of the wall of small airways [139]. Remodelling of the small airways and emphysema contribute to progressive deterioration of respiratory function [140]. Mechanisms leading to these lesions are not yet clearly understood [15, 141]. Recently, SoHAL et al. [141] suggested the implication of EMT in COPD, showing that the basal membrane was altered more in COPD patients who smoked compared with smokers with normal lung function and non-smoking controls. Cells expressing MMP9 and S100A4 were found in the fragmented areas, revealing proteolytic activity and a fibroblast phenotype. These results suggest that fragmentation of the basal membrane could contribute to EMT in vivo $[31,142-144]$. Some immune cells $\left(\mathrm{CD}^{+}\right.$and $\mathrm{CD}^{+}$lymphocytes, macrophages and dendritic cells) were found in the lamina reticularis and in the lamina propia. Cells localised in the fragmentation area of the lamina reticularis poorly expressed cytokeratine, an epithelial marker, and S100A4 [141]. In addition, membrane fragmentation correlated with smoking history in COPD and stopping smoking could reduce the migratory capacity of fibroblastic cells [145]. These studies only used immunohistochemical staining from patient biopsies; therefore, the results do not show whether the cells identified as fibroblasts are from the migration of progenitor cells or from the ability of the epithelium to differentiate into fibroblast-like cells. Although these studies are the first in favour of the implication of EMT during tissue remodelling in COPD, complementary studies are needed to follow in vivo the modification of the epithelial phenotype and cell migration. This type of study would allow a positive control for EMT to be included and to determine whether fragmentation of the lamina reticularis constitutes a key step in COPD progression.

\section{EMT and BO following lung transplantation}

Lung transplantation is the only therapeutic option for patients with terminal respiratory failure. Despite the improvement in immunosuppressive treatments and surgical techniques, chronic lung dysfunction, also 
called BO, is the major limitation of lung transplantation. BO is an irreversible condition with a prevalence of $\sim 50$ and $\sim 75 \%$ at 5 years and 10 years post-transplant, respectively [146]. It is considered to be the result of chronic rejection.

BO is characterised by distal inflammation and fibrosis of the alveoli and bronchi, a process that contributes to bronchial obstruction [147]. BO results from an allogeneic mechanism in which allo-antigens are presented to T-lymphocytes from the recipient $[148,149]$. Even though the immune response plays a role in the development of $\mathrm{BO}$, the respiratory epithelium also contributes to the fibrotic phenomenon. Some studies have described BEC as the major target of the immune response. These cells play a central role in the development of BO [150-152]. MAUCK et al. [150] have shown in vivo that BEC can induce an allo-immune response and express various growth factors that play a role in the development of BO. These results were confirmed by JARAMILLO et al. [151], showing that antibodies against human leukocyte antigen class I are able to activate BEC to secrete fibrotic factors.

The epithelial injury leads to epithelium repair, which could contribute to the fibrotic process when excessive or inappropriate $[147,153,154]$. The cellular mechanisms involved during bronchial remodelling in $\mathrm{BO}$ are not clearly understood. Lung fibroblasts can be derived from fibroblasts in situ or from the recruitment of circulating precursors in the site of inflammation. Recent studies suggest that EMT is implicated during the development of $\mathrm{BO}[29,30,155,156]$, as has been demonstrated for chronic kidney rejection [157-160]. A study with biopsies and ex vivo cultures from lung transplant recipients showed that BEC expressed S100A4 [30]. Secretion of MMP9 was also increased following TGF- $\beta 1$ treatment and BEC were able to invade a collagen gel. This study is the first to demonstrate the effect of TGF- $\beta$ in BEC from lung transplant recipients. It would be interesting to undertake a kinetics study of such cultures in order to determine if the modifications observed in the cell phenotype correspond to a process of tissue repair or to a pathological fibrotic process. In this context, this type of investigation could identify predictive markers of lung remodelling associated with BO. Although this study does not prove a direct link between EMT and $\mathrm{BO}$, it underscores the plasticity of BEC from lung transplant patients. Using flow cytometry, HODGE et al. [156] have demonstrated the increased expression of $\alpha$-SMA and extra domain-fibronectin in BEC from BO patients compared with lung transplant patients without BO. After longitudinal follow-up, the expression of S100A4, $\alpha$-SMA and extra domain-fibronectin was increased [156]. These results, which are yet to be confirmed with a higher number of patients, encourage continuation with such investigations in order to determine if there is a link between myofibroblastic markers and BO.

Studies in the inflammatory environment of BO have shown that TGF- $\beta$ is one of the most important factors involved in the fibrotic process and high levels of TGF- $\beta$ are found in the BAL from BO patients $[148,161-165]$. Other pro-inflammatory cytokines, such as IL-8, TNF- $\alpha$ and IL-1 $\beta$, are also highly expressed in BO patients $[127,148,165]$. This inflammatory environment could contribute to EMT in BO.

BORTHWICK et al. [29] reported that BEC isolated from BO patients could undergo EMT, characterised by a decrease in the expression of E-cadherin and an increase in the expression of vimentin and $\alpha$-SMA. Cotreatment with TGF- $\beta$ and TNF- $\alpha$ accentuates the mesenchymal phenotype. Other inflammatory cytokines such as IL-1 $\beta$ and IL-8 enhance the process of EMT [29]. HGF has also been found in the BAL of BO patients [151]. This growth factor plays a role in the repair of the epithelium following injury and can partially induce EMT $[143,166]$. The dual role of HGF makes it difficult to determine whether it is involved in a physiological EMT during tissue repair or in pathological EMT participating in tissue fibrosis. Other factors from the environment associated with lung transplantation can also play a role in EMT of BO patients. Bacterial infection with Pseudomonas aeruginosa has been shown to significantly increase inflammation in lung transplant recipients [167]. BORTHWICK et al. [168] have shown that bacteria are able to induce EMT in the presence of TGF- $\beta$. This effect is indirect and due to the activation of immune cells [168]. It would be interesting to investigate whether infection with cytomegalovirus, which constitutes a risk factor for $\mathrm{BO}$, can induce EMT. In the chronic rejection of the kidney, immunosuppressive treatments have been described to be involved in EMT [169].

These studies with BEC from lung transplant patients do not allow the origin of fibroblasts contributing to the bronchial obstruction to be determined. This highlights the difficulty in identifying EMT in ex vivo models. Other studies in vitro are necessary to test whether other risk factors (e.g. cytomegalovirus infection or the allogenic context) could contribute to EMT. It would also be interesting to investigate the kinetics of BEC cultures and to correlate the profile of the cells with the clinical stage of lung transplant recipients. It would be then possible to determine if different mesenchymal proteins could be considered as predictive markers of remodelling in BO. 


\section{Conclusions and outlook}

The studies presented here show that EMT is implicated in the bronchial remodelling in chronic pathologies such as asthma, COPD and BO. Given the diversity of markers used to characterise EMT and the variety of study models, the occurrence of EMT is not always easy to demonstrate. Longitudinal studies from patient samples will help determine whether EMT is involved in tissue repair or in a late process contributing to the fibrosis of the tissue.

Studies performed during organ development and metastatic processes have revealed critical signalling pathways involved in EMT. Regarding bronchial pathologies, the same signalling pathways seem to be implicated with a different regulation. It would be of great interest to pursue these studies to determine the mechanism involved in EMT in each bronchial disease and, therefore, distinguish potential therapeutic targets to limit bronchial remodelling.

\section{References}

Hay ED. The mesenchymal cell, its role in the embryo, and the remarkable signaling mechanisms that create it. Dev Dyn 2005; 233: 706-720.

Thiery JP. Epithelial-mesenchymal transitions in tumour progression. Nat Rev Cancer 2002; 2: 442-454.

Ikenouchi J, Matsuda M, Furuse M, et al. Regulation of tight junctions during the epithelium-mesenchyme transition: direct repression of the gene expression of claudins/occludin by Snail. J Cell Sci 2003; 116: 1959-1967. Ozdamar B, Bose R, Barrios-Rodiles M, et al. Regulation of the polarity protein Par6 by TGF $\beta$ receptors controls epithelial cell plasticity. Science 2005; 307: 1603-1609.

5 Guarino M. Epithelial-to-mesenchymal change of differentiation. From embryogenetic mechanism to pathological patterns. Histol Histopathol 1995; 10: 171-184.

6 Vergara D, Merlot B, Lucot JP, et al. Epithelial-mesenchymal transition in ovarian cancer. Cancer Lett 2010; 291: 59-66.

7 Brabletz T, Hlubek F, Spaderna S, et al. Invasion and metastasis in colorectal cancer: epithelial-mesenchymal transition, mesenchymal-epithelial transition, stem cells and $\beta$-catenin. Cells Tissues Organs 2005; 179: 56-65.

8 Usami Y, Satake S, Nakayama F, et al. Snail-associated epithelial-mesenchymal transition promotes oesophageal squamous cell carcinoma motility and progression. J Pathol 2008; 215: 330-339.

9 Trimboli AJ, Fukino K, de Bruin A, et al. Direct evidence for epithelial-mesenchymal transitions in breast cancer. Cancer Res 2008; 68: 937-945.

10 Yáñez-Mó M, Lara-Pezzi E, Selgas R, et al. Peritoneal dialysis and epithelial-to-mesenchymal transition of mesothelial cells. N Engl J Med 2003; 348: 403-413.

11 Saika S. TGF $\beta$ pathobiology in the eye. Lab Invest 2006; 86: 106-115.

12 Rygiel KA, Robertson H, Marshall HL, et al. Epithelial-mesenchymal transition contributes to portal tract fibrogenesis during human chronic liver disease. Lab Invest 2008; 88: 112-123.

13 Selman M, Pardo A. The epithelial/fibroblastic pathway in the pathogenesis of idiopathic pulmonary fibrosis. Am J Respir Cell Mol Biol 2003; 29: Suppl. 3, S93-S97.

14 Selman M, Thannickal VJ, Pardo A, et al. Idiopathic pulmonary fibrosis: pathogenesis and therapeutic approaches. Drugs 2004; 64: 405-430.

15 Willis BC, du Bois RM, Borok Z. Epithelial origin of myofibroblasts during fibrosis in the lung. Proc Am Thorac Soc 2006; 3: 377-382.

16 Antoniades HN, Bravo MA, Avila RE, et al. Platelet-derived growth factor in idiopathic pulmonary fibrosis. J Clin Invest 1990; 86: 1055-1064.

17 Giaid A, Michel RP, Stewart DJ, et al. Expression of endothelin-1 in lungs of patients with cryptogenic fibrosing alveolitis. Lancet 1993; 341: 1550-1554.

18 Khalil N, O'Connor R, Gold LI, et al. Biological effects of transforming growth factor- $\beta 1$ in idiopathic pulmonary fibrosis may be regulated by the activation of latent transforming growth factor- $\beta 1$ and the differential expression of transforming growth factor- $\beta$ receptors. Chest 2001; 120: Suppl. 1, 48S.

19 Khalil N, O'Connor RN, Unruh HW, et al. Increased production and immunohistochemical localization of transforming growth factor- $\beta$ in idiopathic pulmonary fibrosis. Am J Respir Cell Mol Biol 1991; 5: 155-162.

20 Khalil N, O'Connor RN, Flanders KC, et al. TGF- $\beta 1$, but not TGF- $\beta 2$ or TGF- $\beta 3$, is differentially present in epithelial cells of advanced pulmonary fibrosis: an immunohistochemical study. Am J Respir Cell Mol Biol 1996; 14: 131-138.

21 Nash JR, McLaughlin PJ, Butcher D, et al. Expression of tumour necrosis factor- $\alpha$ in cryptogenic fibrosing alveolitis. Histopathology 1993; 22: 343-347.

22 Pan LH, Yamauchi K, Uzuki M, et al. Type II alveolar epithelial cells and interstitial fibroblasts express connective tissue growth factor in IPF. Eur Respir J 2001; 17: 1220-1227.

23 Kim KK, Kugler MC, Wolters PJ, et al. Alveolar epithelial cell mesenchymal transition develops in vivo during pulmonary fibrosis and is regulated by the extracellular matrix. Proc Natl Acad Sci USA 2006; 103: 13180-13185.

24 Kasai H, Allen JT, Mason RM, et al. TGF- $\beta 1$ induces human alveolar epithelial to mesenchymal cell transition (EMT). Respir Res 2005; 6: 56.

25 Zuo F, Kaminski N, Eugui E, et al. Gene expression analysis reveals matrilysin as a key regulator of pulmonary fibrosis in mice and humans. Proc Natl Acad Sci USA 2002; 99: 6292-6297.

26 Selman M, Ruiz V, Cabrera S, et al. TIMP-1, -2, -3, and -4 in idiopathic pulmonary fibrosis. A prevailing nondegradative lung microenvironment? Am J Physiol Lung Cell Mol Physiol 2000; 279: L562-L574.

27 Holgate ST, Davies DE, Puddicombe S, et al. Mechanisms of airway epithelial damage: epithelial-mesenchymal interactions in the pathogenesis of asthma. Eur Respir J 2003; 22: Suppl. 44, 24s-29s.

Flanders KC. Smad3 as a mediator of the fibrotic response. Int J Exp Pathol 2004; 85: 47-64.

29 Borthwick LA, Parker SM, Brougham KA, et al. Epithelial to mesenchymal transition (EMT) and airway remodelling after human lung transplantation. Thorax 2009; 64: 770-777. 
30 Ward C, Forrest IA, Murphy DM, et al. Phenotype of airway epithelial cells suggests epithelial to mesenchymal cell transition in clinically stable lung transplant recipients. Thorax 2005; 60: 865-871.

31 Kalluri R. EMT: when epithelial cells decide to become mesenchymal-like cells. J Clin Invest 2009; 119: 1417-1419.

32 Tanimizu N, Miyajima A. Molecular mechanism of liver development and regeneration. Int Rev Cytol 2007; 259: 1-48.

33 Johansson KA, Grapin-Botton A. Development and diseases of the pancreas. Clin Genet 2002; 62: 14-23.

34 Nakajima Y, Yamagishi T, Hokari S, et al. Mechanisms involved in valvuloseptal endocardial cushion formation in early cardiogenesis: roles of transforming growth factor (TGF)- $\beta$ and bone morphogenetic protein (BMP). Anat Rec 2000; 258: 119-127.

35 Nawshad A, Lagamba D, Polad A, et al. Transforming growth factor- $\beta$ signaling during epithelial-mesenchymal transformation: implications for embryogenesis and tumor metastasis. Cells Tissues Organs 2005; 179: 11-23.

36 Maestro R, Dei Tos AP, Hamamori Y, et al. Twist is a potential oncogene that inhibits apoptosis. Genes Dev 1999; 13: 2207-2217.

37 Vega S, Morales AV, Ocaña OH, et al. Snail blocks the cell cycle and confers resistance to cell death. Genes Dev 2004; 18: 1131-1143.

38 Yang J, Weinberg RA. Epithelial-mesenchymal transition: at the crossroads of development and tumor metastasis. Dev Cell 2008; 14: 818-829.

39 Fidler IJ, Poste G. The "seed and soil" hypothesis revisited. Lancet Oncol 2008; 9: 808.

40 Iwano M, Plieth D, Danoff TM, et al. Evidence that fibroblasts derive from epithelium during tissue fibrosis. J Clin Invest 2002; 110: 341-350.

41 Guarino M, Tosoni A, Nebuloni M. Direct contribution of epithelium to organ fibrosis: epithelial-mesenchymal transition. Hum Pathol 2009; 40: 1365-1376.

42 Lee JM, Dedhar S, Kalluri R, et al. The epithelial-mesenchymal transition: new insights in signaling, development, and disease. J Cell Biol 2006; 172: 973-981.

43 Okada H, Ban S, Nagao S, et al. Progressive renal fibrosis in murine polycystic kidney disease: an immunohistochemical observation. Kidney Int 2000; 58: 587-597.

44 Serini G, Gabbiani G. Mechanisms of myofibroblast activity and phenotypic modulation. Exp Cell Res 1999; 250: 273-283.

45 Gibbs FE, Barraclough R, Platt-Higgins A, et al. Immunocytochemical distribution of the calcium-binding protein p9Ka in normal rat tissues: variation in the cellular location in different tissues. J Histochem Cytochem 1995; 43: 169-180.

46 Inoue $\mathrm{T}$, Plieth $\mathrm{D}$, Venkov $\mathrm{CD}$, et al. Antibodies against macrophages that overlap in specificity with fibroblasts. Kidney Int 2005; 67: 2488-2493.

47 Le Hir M, Hegyi I, Cueni-Loffing D, et al. Characterization of renal interstitial fibroblast-specific protein 1/S100A4positive cells in healthy and inflamed rodent kidneys. Histochem Cell Biol 2005; 123: 335-346.

48 Strutz F, Okada H, Lo CW, et al. Identification and characterization of a fibroblast marker: FSP1. J Cell Biol 1995; 130: 393-405.

49 Janda E, Lehmann K, Killisch I, et al. Ras and TGF $\beta$ cooperatively regulate epithelial cell plasticity and metastasis: dissection of Ras signaling pathways. J Cell Biol 2002; 156: 299-313.

50 Cano A, Pérez-Moreno MA, Rodrigo I, et al. The transcription factor snail controls epithelial-mesenchymal transitions by repressing E-cadherin expression. Nat Cell Biol 2000; 2: 76-83.

Huber MA, Beug H, Wirth T. Epithelial-mesenchymal transition: NF-кB takes center stage. Cell cycle 2004; 3: 1477-1480. Nieto MA. The snail superfamily of zinc-finger transcription factors. Nat Rev Mol Cell Biol 2002; 3: 155-166.

53 Peinado H, Quintanilla M, Cano A. Transforming growth factor $\beta-1$ induces snail transcription factor in epithelial cell lines: mechanisms for epithelial mesenchymal transitions. J Biol Chem 2003; 278: 21113-21123.

Radisky DC. Epithelial-mesenchymal transition. J Cell Sci 2005; 118: 4325-4326.

Finkel T. Oxidant signals and oxidative stress. Curr Opin Cell Biol 2003; 15: 247-254.

Hussain SP, Hofseth LJ, Harris CC. Radical causes of cancer. Nat Rev Cancer 2003; 3: 276-285.

Morali OG, Delmas V, Moore R, et al. IGF-II induces rapid $\beta$-catenin relocation to the nucleus during epithelium to mesenchyme transition. Oncogene 2001; 20: 4942-4950.

58 Strutz F, Zeisberg M, Ziyadeh FN, et al. Role of basic fibroblast growth factor-2 in epithelial-mesenchymal transformation. Kidney Int 2002; 61: 1714-1728.

59 Mizuno S, Kurosawa T, Matsumoto K, et al. Hepatocyte growth factor prevents renal fibrosis and dysfunction in a mouse model of chronic renal disease. J Clin Invest 1998; 101: 1827-1834.

60 Nawshad A, LaGamba D, Hay ED. Transforming growth factor $\beta$ (TGF $\beta$ ) signalling in palatal growth, apoptosis and epithelial mesenchymal transformation (EMT). Arch Oral Biol 2004; 49: 675-689.

61 Sridurongrit S, Larsson J, Schwartz R, et al. Signaling via the TGF- $\beta$ type I receptor Alk5 in heart development. Dev Biol 2008; 322: 208-218.

62 Nawshad A, Medici D, Liu CC, et al. TGF $\beta 3$ inhibits E-cadherin gene expression in palate medial-edge epithelial cells through a Smad2-Smad4-LEF1 transcription complex. J Cell Sci 2007; 120: 1646-1653.

63 Hackett TL, Warner SM, Stefanowicz D, et al. Induction of epithelial-mesenchymal transition in primary airway epithelial cells from patients with asthma by transforming growth factor- $\beta 1$. Am J Respir Crit Care Med 2009; 180: $122-133$

64 Heijink IH, Postma DS, Noordhoek JA, et al. House dust mite-promoted epithelial-to-mesenchymal transition in human bronchial epithelium. Am J Respir Cell Mol Biol 2010; 42: 69-79.

65 Gardner A, Fisher AJ, Richter C, et al. The critical role of TAK1 in accentuated epithelial to mesenchymal transition in obliterative bronchiolitis after lung transplantation. Am J Pathol 2012; 180: 2293-2308.

66 Câmara J, Jarai G. Epithelial-mesenchymal transition in primary human bronchial epithelial cells is Smaddependent and enhanced by fibronectin and TNF- $\alpha$. Fibrogenesis Tissue Repair 2010; 3: 2.

67 Doerner AM, Zuraw BL. TGF- $\beta 1$ induced epithelial to mesenchymal transition (EMT) in human bronchial epithelial cells is enhanced by IL-1 $\beta$ but not abrogated by corticosteroids. Respir Res 2009; 10: 100.

68 Zhang M, Zhang Z, Pan HY, et al. TGF- $\beta 1$ induces human bronchial epithelial cell-to-mesenchymal transition in vitro. Lung 2009; 187: 187-194.

69 Massagué J. How cells read TGF- $\beta$ signals. Nat Rev Mol Cell Biol 2000; 1: 169-178. 
Fuxe J, Vincent T, Garcia de Herreros A. Transcriptional crosstalk between TGF- $\beta$ and stem cell pathways in tumor cell invasion: role of EMT promoting Smad complexes. Cell Cycle 2010; 9: 2363-2374.

71 Derynck R, Zhang YE. Smad-dependent and Smad-independent pathways in TGF- $\beta$ family signalling. Nature 2003; 425: $577-584$

72 Thuault S, Valcourt U, Petersen M, et al. Transforming growth factor- $\beta$ employs HMGA2 to elicit epithelialmesenchymal transition. J Cell Biol 2006; 174: 175-183.

73 Barrallo-Gimeno A, Nieto MA. The Snail genes as inducers of cell movement and survival: implications in development and cancer. Development 2005; 132: 3151-3161.

74 Olmeda D, Jordá M, Peinado H, et al. Snail silencing effectively suppresses tumour growth and invasiveness. Oncogene 2007; 26: 1862-1874.

75 Zavadil J, Cermak L, Soto-Nieves N, et al. Integration of TGF- $\beta /$ Smad and Jagged1/Notch signalling in epithelialto-mesenchymal transition. EMBO J 2004; 23: 1155-1165.

76 Dumont N, Arteaga CL. Targeting the TGF $\beta$ signaling network in human neoplasia. Cancer Cell 2003; 3: 531-536.

77 Yingling JM, Blanchard KL, Sawyer JS. Development of TGF- $\beta$ signalling inhibitors for cancer therapy. Nat Rev Drug Discov 2004; 3: 1011-1022.

78 Subramanian G, Schwarz RE, Higgins L, et al. Targeting endogenous transforming growth factor $\beta$ receptor signaling in SMAD4-deficient human pancreatic carcinoma cells inhibits their invasive phenotype1. Cancer Res 2004; 64: 5200-5211.

79 Willis BC, Borok Z. TGF- $\beta$-induced EMT: mechanisms and implications for fibrotic lung disease. Am J Physiol Lung Cell Mol Physiol 2007; 293: L525-L534.

80 Zeisberg M, Hanai J, Sugimoto H, et al. BMP-7 counteracts TGF- $\beta 1$-induced epithelial-to-mesenchymal transition and reverses chronic renal injury. Nat Med 2003; 9: 964-968.

81 Zeisberg M, Bottiglio C, Kumar N, et al. Bone morphogenic protein-7 inhibits progression of chronic renal fibrosis associated with two genetic mouse models. Am J Physiol Renal Physiol 2003; 285: F1060-F1067.

82 Thiery JP. Epithelial-mesenchymal transitions in development and pathologies. Curr Opin Cell Biol 2003; 15 : 740-746.

83 Ellenrieder V, Hendler SF, Boeck W, et al. Transforming growth factor $\beta 1$ treatment leads to an epithelialmesenchymal transdifferentiation of pancreatic cancer cells requiring extracellular signal-regulated kinase 2 activation. Cancer Res 2001; 61: 4222-4228.

84 Bates RC, Mercurio AM. Tumor necrosis factor- $\alpha$ stimulates the epithelial-to-mesenchymal transition of human colonic organoids. Mol Biol Cell 2003; 14: 1790-1800.

85 Xie L, Law BK, Chytil AM, et al. Activation of the Erk pathway is required for TGF- $\beta 1$-induced EMT in vitro. Neoplasia 2004; 6: 603-610.

86 Zavadil J, Böttinger EP. TGF- $\beta$ and epithelial-to-mesenchymal transitions. Oncogene 2005; 24: 5764-5774.

87 Pongracz JE, Stockley RA. Wnt signalling in lung development and diseases. Respir Res 2006; 7: 15.

88 Zavadil J, Bitzer M, Liang D, et al. Genetic programs of epithelial cell plasticity directed by transforming growth factor- $\beta$. Proc Natl Acad Sci USA 2001; 98: 6686-6691.

89 Shin SY, Rath O, Zebisch A, et al. Functional roles of multiple feedback loops in extracellular signal-regulated kinase and Wnt signaling pathways that regulate epithelial-mesenchymal transition. Cancer Res 2010; 70: 6715-6724.

90 Eger A, Stockinger A, Park J, et al. $\beta$-Catenin and TGF $\beta$ signalling cooperate to maintain a mesenchymal phenotype after FosER-induced epithelial to mesenchymal transition. Oncogene 2004; 23: 2672-2680.

91 Morin PJ. $\beta$-catenin signaling and cancer. Bioessays 1999; 21: 1021-1030.

92 Königshoff M, Eickelberg O. WNT signaling in lung disease: a failure or a regeneration signal? Am J Respir Cell Mol Biol 2010; 42: 21-31.

93 Königshoff M, Balsara N, Pfaff EM, et al. Functional Wnt signaling is increased in idiopathic pulmonary fibrosis. PLoS One 2008; 3: e2142.

94 Timmerman LA, Grego-Bessa J, Raya A, et al. Notch promotes epithelial-mesenchymal transition during cardiac development and oncogenic transformation. Genes Dev 2004; 18: 99-115.

95 Karhadkar SS, Bova GS, Abdallah N, et al. Hedgehog signalling in prostate regeneration, neoplasia and metastasis. Nature 2004; 431: 707-712.

96 Nüsslein-Volhard C, Wieschaus E. Mutations affecting segment number and polarity in Drosophila. Nature 1980; 287: 795-801.

97 Varjosalo M, Taipale J. Hedgehog: functions and mechanisms. Genes Dev 2008; 22: 2454-2472

98 Stecca B, Ruiz I, Altaba A. Context-dependent regulation of the GLI code in cancer by HEDGEHOG and nonHEDGEHOG signals. J Mol Cell Biol 2010; 2: 84-95.

99 Watkins DN, Berman DM, Burkholder SG, et al. Hedgehog signalling within airway epithelial progenitors and in small-cell lung cancer. Nature 2003; 422: 313-317.

100 Bellusci S, Furuta Y, Rush MG, et al. Involvement of Sonic hedgehog (Shh) in mouse embryonic lung growth and morphogenesis. Development 1997; 124: 53-63.

101 Litingtung Y, Lei L, Westphal H, et al. Sonic hedgehog is essential to foregut development. Nat Genet 1998; 20 : 58-61.

102 Pepicelli CV, Lewis PM, McMahon AP. Sonic hedgehog regulates branching morphogenesis in the mammalian lung. Curr Biol 1998; 8: 1083-1086.

103 Motoyama J, Liu J, Mo R, et al. Essential function of Gli2 and Gli3 in the formation of lung, trachea and oesophagus. Nat Genet 1998; 20: 54-57.

104 Wang K, Pan L, Che X, et al. Sonic Hedgehog/GLI? signaling pathway inhibition restricts cell migration and invasion in human gliomas. Neurol Res 2010; 32: 975-980.

105 Li X, Deng W, Nail CD, et al. Snail induction is an early response to Glil that determines the efficiency of epithelial transformation. Oncogene 2006; 25: 609-621.

106 Joost S, Almada LL, Rohnalter V, et al. GLI1 inhibition promotes epithelial-to-mesenchymal transition in pancreatic cancer cells. Cancer Res 2012; 72: 88-99.

107 Ohta H, Aoyagi K, Fukaya M, et al. Cross talk between hedgehog and epithelial-mesenchymal transition pathways in gastric pit cells and in diffuse-type gastric cancers. Br J Cancer 2009; 100: 389-398.

108 Syn WK, Jung Y, Omenetti A, et al. Hedgehog-mediated epithelial-to-mesenchymal transition and fibrogenic repair in nonalcoholic fatty liver disease. Gastroenterology 2009; 137: 1478-1488.e8. 
109 Coon DR, Roberts DJ, Loscertales M, et al. Differential epithelial expression of SHH and FOXF1 in usual and nonspecific interstitial pneumonia. Exp Mol Pathol 2006; 80: 119-123.

110 Stewart GA, Hoyne GF, Ahmad SA, et al. Expression of the developmental Sonic hedgehog (Shh) signalling pathway is up-regulated in chronic lung fibrosis and the Shh receptor patched 1 is present in circulating $\mathrm{T}$ lymphocytes. J Pathol 2003; 199: 488-495.

111 Cigna N, Farrokhi Moshai E, Brayer S, et al. The hedgehog system machinery controls transforming growth factor- $\beta$-dependent myofibroblastic differentiation in humans: involvement in idiopathic pulmonary fibrosis. $\mathrm{Am} \mathrm{J}$ Pathol 2012; 181: 2126-2137.

112 Bolaños AL, Milla CM, Lira JC, et al. Role of Sonic Hedgehog in idiopathic pulmonary fibrosis. Am J Physiol Lung Cell Mol Physiol 2012; 303: L978-L990.

113 Bermudez O, Hennen E, Koch I, et al. Glil mediates lung cancer cell proliferation and sonic hedgehog-dependent mesenchymal cell activation. PLoS One 2013; 8: e63226.

114 Park KS, Martelotto LG, Peifer M, et al. A crucial requirement for Hedgehog signaling in small cell lung cancer. Nat Med 2011; 17: 1504-1508.

115 Yuan Z, Goetz JA, Singh S, et al. Frequent requirement of hedgehog signaling in non-small cell lung carcinoma. Oncogene 2007; 26: 1046-1055.

116 Chi S, Huang S, Li C, et al. Activation of the hedgehog pathway in a subset of lung cancers. Cancer Lett 2006; 244: 53-60.

117 Varnat F, Duquet A, Malerba M, et al. Human colon cancer epithelial cells harbour active HEDGEHOG-GLI signalling that is essential for tumour growth, recurrence, metastasis and stem cell survival and expansion. EMBO Mol Med 2009; 1: 338-351.

118 Lipinski RJ, Bijlsma MF, Gipp JJ, et al. Establishment and characterization of immortalized Gli-null mouse embryonic fibroblast cell lines. BMC Cell Biol 2008; 9: 49.

119 Polizio AH, Chinchilla P, Chen X, et al. Sonic Hedgehog activates the GTPases Racl and RhoA in a Gliindependent manner through coupling of smoothened to Gi proteins. Sci Signal 2011; 4: pt7.

120 Dennler S, André J, Verrecchia F, et al. Cloning of the human GLI2 promoter: transcriptional activation by transforming growth factor- $\beta$ via SMAD3/ $\beta$-catenin cooperation. J Biol Chem 2009; 284: 31523-31531.

121 Nolan-Stevaux O, Lau J, Truitt ML, et al. GLI1 is regulated through Smoothened-independent mechanisms in neoplastic pancreatic ducts and mediates PDAC cell survival and transformation. Genes Dev 2009; 23: 24-36.

122 Javelaud D, Pierrat MJ, Mauviel A. Crosstalk between TGF- $\beta$ and hedgehog signaling in cancer. FEBS Lett 2012; 586: 2016-2025.

123 Elias JA, Lee CG, Zheng T, et al. New insights into the pathogenesis of asthma. J Clin Invest 2003; 111: 291-297.

124 Payne DNR, Rogers AV, Adelroth E, et al. Early thickening of the reticular basement membrane in children with difficult asthma. Am J Respir Crit Care Med 2003; 167: 78-82.

125 Cokuğraş H, Akçakaya N, Seçkin, et al. Ultrastructural examination of bronchial biopsy specimens from children with moderate asthma. Thorax 2001; 56: 25-29.

126 Nawijn MC, Hackett TL, Postma DS, et al. E-cadherin: gatekeeper of airway mucosa and allergic sensitization. Trends Immunol 2011; 32: 248-255.

127 Magnan A, Frachon I, Rain B, et al. Transforming growth factor $\beta$ in normal human lung: preferential location in bronchial epithelial cells. Thorax 1994; 49: 789-792.

128 Nihlberg K, Larsen K, Hultgårdh-Nilsson A, et al. Tissue fibrocytes in patients with mild asthma: a possible link to thickness of reticular basement membrane? Respir Res 2006; 7: 50.

129 Johnson JR, Roos A, Berg T, et al. Chronic respiratory aeroallergen exposure in mice induces epithelialmesenchymal transition in the large airways. PLoS One 2011; 6: e16175.

130 Wan H, Winton HL, Soeller C, et al. Der p 1 facilitates transepithelial allergen delivery by disruption of tight junctions. J Clin Invest 1999; 104: 123-133.

131 Runswick S, Mitchell T, Davies P, et al. Pollen proteolytic enzymes degrade tight junctions. Respirology 2007; 12: 834-842.

132 Redington AE, Madden J, Frew AJ, et al. Transforming growth factor- $\beta 1$ in asthma. Measurement in bronchoalveolar lavage fluid. Am J Respir Crit Care Med 1997; 156: 642-647.

133 Chakir J, Shannon J, Molet S, et al. Airway remodeling-associated mediators in moderate to severe asthma: effect of steroids on TGF- $\beta$, IL-11, IL-17, and type I and type III collagen expression. J Allergy Clin Immunol 2003; 111: 1293-1298.

134 Yamaguchi M, Niimi A, Matsumoto $\mathrm{H}$, et al. Sputum levels of transforming growth factor- $\beta 1$ in asthma: relation to clinical and computed tomography findings. J Investig Allergol Clin Immunol 2008; 18: 202-206.

135 Vignola AM, Merendino AM, Chiappara G, et al. Markers of acute airway inflammation. Monaldi Arch Chest Dis 1997; 52: 83-85.

136 Churg A, Tai H, Coulthard T, et al. Cigarette smoke drives small airway remodeling by induction of growth factors in the airway wall. Am J Respir Crit Care Med 2006; 174: 1327-1334.

137 Hogg JC, Macklem PT, Thurlbeck WM. Site and nature of airway obstruction in chronic obstructive lung disease. N Engl J Med 1968; 278: 1355-1360.

138 Saetta M, Turato G, Baraldo S, et al. Goblet cell hyperplasia and epithelial inflammation in peripheral airways of smokers with both symptoms of chronic bronchitis and chronic airflow limitation. Am J Respir Crit Care Med 2000; 161: 1016-1021.

139 Hogg JC, Timens W. The pathology of chronic obstructive pulmonary disease. Annu Rev Pathol 2009; 4: 435-459.

140 O’Donnell DE, Parker CM. COPD exacerbations. 3: Pathophysiology. Thorax 2006; 61: 354-361.

141 Sohal SS, Reid D, Soltani A, et al. Reticular basement membrane fragmentation and potential epithelial mesenchymal transition is exaggerated in the airways of smokers with chronic obstructive pulmonary disease. Respirology 2010; 15: 930-938.

142 Acloque H, Adams MS, Fishwick K, et al. Epithelial-mesenchymal transitions: the importance of changing cell state in development and disease. J Clin Invest 2009; 119: 1438-1449.

143 Kalluri R, Neilson EG. Epithelial-mesenchymal transition and its implications for fibrosis. J Clin Invest 2003; 112: 1776-1784.

144 Zeisberg M, Neilson EG. Biomarkers for epithelial-mesenchymal transitions. J Clin Invest 2009; 119: 1429-1437. 
145 Soltani A, Reid DW, Sohal SS, et al. Basement membrane and vascular remodelling in smokers and chronic obstructive pulmonary disease: a cross-sectional study. Respir Res 2010; 11: 105.

146 Christie JD, Edwards LB, Kucheryavaya AY, et al. The Registry of the International Society for Heart and Lung Transplantation: twenty-seventh official adult lung and heart-lung transplant report - 2010. J Heart Lung Transplant 2010; 29: 1104-1118.

147 Estenne M, Hertz MI. Bronchiolitis obliterans after human lung transplantation. Am J Respir Crit Care Med 2002; 166: 440-444.

148 Riise GC, Williams A, Kjellström C, et al. Bronchiolitis obliterans syndrome in lung transplant recipients is associated with increased neutrophil activity and decreased antioxidant status in the lung. Eur Respir J 1998; 12: 82-88.

149 Trulock EP. Lung transplantation. Am J Respir Crit Care Med 1997; 155: 789-818.

150 Mauck KA, Hosenpud JD. The bronchial epithelium: a potential allogeneic target for chronic rejection after lung transplantation. J Heart Lung Transplant 1996; 15: 709-714.

151 Jaramillo A, Smith CR, Maruyama T, et al. Anti-HLA class I antibody binding to airway epithelial cells induces production of fibrogenic growth factors and apoptotic cell death: a possible mechanism for bronchiolitis obliterans syndrome. Hum Immunol 2003; 64: 521-529.

152 Fernández FG, Jaramillo A, Chen C, et al. Airway epithelium is the primary target of allograft rejection in murine obliterative airway disease. Am J Transplant 2004; 4: 319-325.

153 Boehler A, Estenne M. Post-transplant bronchiolitis obliterans. Eur Respir J 2003; 22: 1007-1018.

154 Yousem SA. Significance of clinically silent untreated mild acute cellular rejection in lung allograft recipients. Hum Pathol 1996; 27: 269-273.

155 Borthwick LA, McIlroy EI, Gorowiec MR, et al. Inflammation and epithelial to mesenchymal transition in lung transplant recipients: role in dysregulated epithelial wound repair. Am J Transplant 2010; 10: 498-509.

156 Hodge S, Holmes M, Banerjee B, et al. Posttransplant bronchiolitis obliterans syndrome is associated with bronchial epithelial to mesenchymal transition. Am J Transplant 2009; 9: 727-733.

157 Robertson H, Ali S, McDonnell BJ, et al. Chronic renal allograft dysfunction: the role of T cell-mediated tubular epithelial to mesenchymal cell transition. J Am Soc Nephrol 2004; 15: 390-397.

158 Rastaldi MP. Epithelial-mesenchymal transition and its implications for the development of renal tubulointerstitial fibrosis. J Nephrol 2006; 19: 407-412.

159 Hertig A. [Epithelial-mesenchymal transition of the renal graft]. Nephrol Ther 2008; 4: Suppl. 1, S25-S28.

160 Bedi S, Vidyasagar A, Djamali A. Epithelial-to-mesenchymal transition and chronic allograft tubulointerstitial fibrosis. Transplant Rev (Orlando) 2008; 22: 1-5.

161 El-Gamel A, Awad M, Sim E, et al. Transforming growth factor- $\beta 1$ and lung allograft fibrosis. Eur J Cardiothorac Surg 1998; 13: 424-430.

162 Elssner A, Jaumann F, Dobmann S, et al. Elevated levels of interleukin-8 and transforming growth factor- $\beta$ in bronchoalveolar lavage fluid from patients with bronchiolitis obliterans syndrome: proinflammatory role of bronchial epithelial cells. Munich Lung Transplant Group. Transplantation 2000; 70: 362-367.

163 Magnan A, Mege JL, Escallier JC, et al. Balance between alveolar macrophage IL-6 and TGF- $\beta$ in lung-transplant recipients. Marseille and Montréal Lung Transplantation Group. Am J Respir Crit Care Med 1996; 153: 1431-1436.

164 Bergmann M, Tiroke A, Schäfer H, et al. Gene expression of profibrotic mediators in bronchiolitis obliterans syndrome after lung transplantation. Scand Cardiovasc J 1998; 32: 97-103.

165 Vanaudenaerde BM, Wuyts WA, Geudens N, et al. Broncho-alveolar lavage fluid recovery correlates with airway neutrophilia in lung transplant patients. Respir Med 2008; 102: 339-347.

166 Myerburg MM, Latoche JD, McKenna EE, et al. Hepatocyte growth factor and other fibroblast secretions modulate the phenotype of human bronchial epithelial cells. Am J Physiol Lung Cell Mol Physiol 2007; 292: L1352-L1360.

167 Vos R, Vanaudenaerde BM, Geudens N, et al. Pseudomonal airway colonisation: risk factor for bronchiolitis obliterans syndrome after lung transplantation? Eur Respir J 2008; 31: 1037-1045.

168 Borthwick LA, Sunny SS, Oliphant V, et al. Pseudomonas aeruginosa accentuates epithelial-to-mesenchymal transition in the airway. Eur Respir J 2011; 37: 1237-1247.

169 Strutz F. Pathogenesis of tubulointerstitial fibrosis in chronic allograft dysfunction. Clin Transplant 2009; 23: Suppl. 21, 26-32. 